\title{
A Virtual Reality Teaching System for Graphic Design Course
}

\author{
https://doi.org/10.3991/ijet.v12.i09.7492 \\ Mingying Lou \\ University of Science and Technology Liaoning, Anshan, Liaoning \\ mingying10567@163.com
}

\begin{abstract}
Graphic design is a comprehensive science integrating artistry, innovation and operability. Graphic design is not limited to print media any more, but starts to be combined with multi-dimensional design methods. The traditional dull duck-stuffing teaching method is not good for stimulating students' enthusiasm for study, creativity and imagination, and cannot meet students' learning need accordingly. Thus, we intend to combine paintingimitating teaching with virtual reality in the course of graphic design, with an aim to make up the deficiency of traditional teaching mode, stimulate students' enthusiasm for study and learning motivation, arouse students' imagination, creativity and sensibility, and improve students' overall design capability. To check the effect of the combination of painting-imitating teaching and virtual reality in course teaching of graphic design, we carried out a case study of course teaching of graphic design. The results demonstrate that the class for which virtual reality teaching tools was adopted is significantly superior to the class for which the traditional teaching method was adopted in respect of the degree of proficiency of course teaching skills, special imagination, students' concentration, and consolidation of knowledge after class, especially in respect of students' concentration and special imagination. These findings indicate the combination of painting-imitating teaching and virtual reality is helpful to stimulate students' learning initiative, enthusiasm for study, and learning interest, and greatly improve learning effect.
\end{abstract}

Keywords-Virtual reality technology, painting-imitating teaching, graphic design, multimedia

\section{Introduction}

Graphic design is also referred to as visual communication design. Traditional graphic design mainly refers to two-dimensional artistic creation based on print media. With the diversification of media form, the audience objectives of graphic design are becoming more and more choosy, and not satisfied with ordinary material arrangement and print media [1]. Traditional graphic design with dull form of representation is little attractive to the audience objectives. The change of design tools and the improvement of output technology provide new possibilities to graphic design, and design media also has become more diversified from traditional print media and ex- 
tended to new media such as digital media. For the learners and practitioners of graphic design, the traditional design mode and tools greatly limit their creativity, so it is difficult for them to resonate with each other. Only by applying novel design creativity and advanced design methods in graphic design creation and making great efforts to realize balanced development of students' artistic accomplishment and technical capacity, students can create appealing and impressive works[2]. How to employ mature technological tools and advanced teaching mode to serve the science of graphic design has been being a focal point of exploration and research in the field of graphic design. The emergence of new high-tech means provides a new idea and method for solving the problems in the learning of graphic design. We certainly can break down the barriers of traditional education and optimize the traditional education mode by combining new design tools and the science of graphic design based on the traditional graphic design course and in reliance upon new media technology.

\section{State of the art}

Presently, virtual reality technology is applied in teaching more and more widely both at home and abroad, such as military teaching [3], athletic training [4], medical simulation training [5], aircraft piloting and automobile driving [6], and instrument operation. Virtual reality technology can create a lifelike environment for teachers and students. The combination of virtual reality technology with proper equipment can put students and teachers in a virtual environment, and return the modification and operation of model [5], to realize real-time information interaction and solve the problem of delayed feedback of traditional teaching mode. There is a virtual reality application software-VRChat [7] different from ordinary instant communication software in that VRChat can map users into an online "room" via certain equipment and realize real-time interaction with other users mapped into the "room". Thanks to its characteristics, the University of British Columbia made use of it to carry out distance teaching, having realized the combination of virtual reality technology with education to a certain extent.

Comparing with foreign researchers, Chinese researchers started studying virtual reality technology late, and mainly apply virtual reality technology to realize virtual campus. With respect to subject distribution, virtual reality technology is widely applied in science and engineering and operation training [8], in particular in subject teaching that is hazardous or needs much manpower, material resources and financial resources. Many Chinese universities have made related attempts and explorations, such as the college physics virtual reality platform of the University of Science and Technology of China [9], the architectural design virtual system of Tongji University [10], and the flight model system of Beihang University [11]. The advantages of virtual reality technology include cost reduction, economical and efficient output, and risk reduction [9-11]. According to the advanced experience of applying virtual reality technology in other fields, the virtual reality technology is also of a broad application prospect in the field of graphic design. 
Thanks to multimedia technology, the presentation of graphic design is not limited to two-dimensional surface any more, but starts to be combined with threedimensional space and virtual space, to present design more visual and vivid. It has become an inexorable trend of educational development to apply multimedia technology and virtual reality technology in education. But there are also some limitations in the process of applying virtual reality technology in teaching. Firstly, most universities still adhere to the traditional teaching method in the application of virtual reality technology in classroom teaching, so the actual result is not as ideal as we expect. Secondly, there is no professional learning software to support teaching, so that teaching cannot keep pace with practice. The innovative point of this research includes the combination of painting-imitating teaching with virtual reality technology and professional graphic design software, and the application of the combination in the teaching process of graphic design. A professional graphic design assistant software is employed. This software is provided with visual user interface, which is easy to operate, and can help students design professional and unique work. The painting-imitating teaching method is adopted. The painting-imitating teaching method is featured by that students can be guided to imitate effect pictures in different ways in teaching process, the degree of proficiency of students in knowledge and skills can be learned about, students' experience can be enriched, a full play can be given to students' subjective initiative, and students can be motivated to acquire new knowledge constantly.

\section{Theoretical basis}

\subsection{Virtual reality technology}

As shown in Fig. 1, virtual reality technology has three features: interaction, immersive, and imagination [12]. Immersive means that user can feel personally on the three-dimensional scene via the presentation of virtual model, so that user changes from passive receiver into participant. Interaction means that real-time response to and feedback of the built model can be given by modifying and configuring parameters, so that the design cycle can be reduced, and the manpower and financial resources required for repeated modification of traditional design also can be reduced. Imagination means that the contents that cannot be realized and experienced in the real world for reasons of technology or cost can be imagined via the virtual reality technology, and a model can be built for simulation on this basis.

As shown in Fig. 2, a virtual reality system mainly consists of 5 modules: user, computer module, software system, database and input and output devices. User is the audience of virtual content, who makes intuitive response to the virtual content produced by the virtual reality system. The computer module is the key component of the whole system, which is responsible for generating virtual content and conversion of instructions transmitted via the input and output devices and digital signals of computer. The software system is for modeling of virtual content, modifying and changing model at the time of modifying parameters, and integrating videos, audios and models. The database is for storing parameter information required for modeling and 
materials required for producing virtual content, such as image, voice, video, and so on. The input and output devices are the interactive link between user and virtual content, the input device converts user's intention into instructions and transfers the instructions to computer, and the output device presents the formed virtual content to user in some way, to produce visual response.

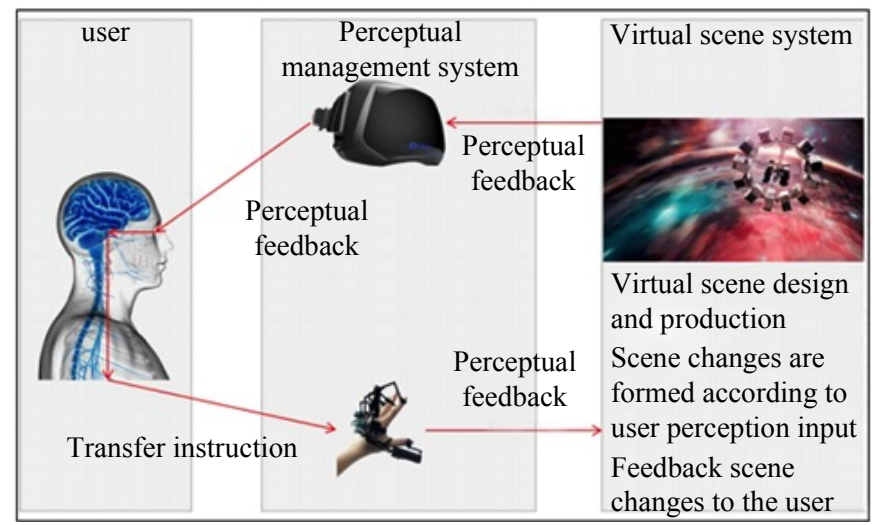

Fig. 1. Virtual reality technology principle

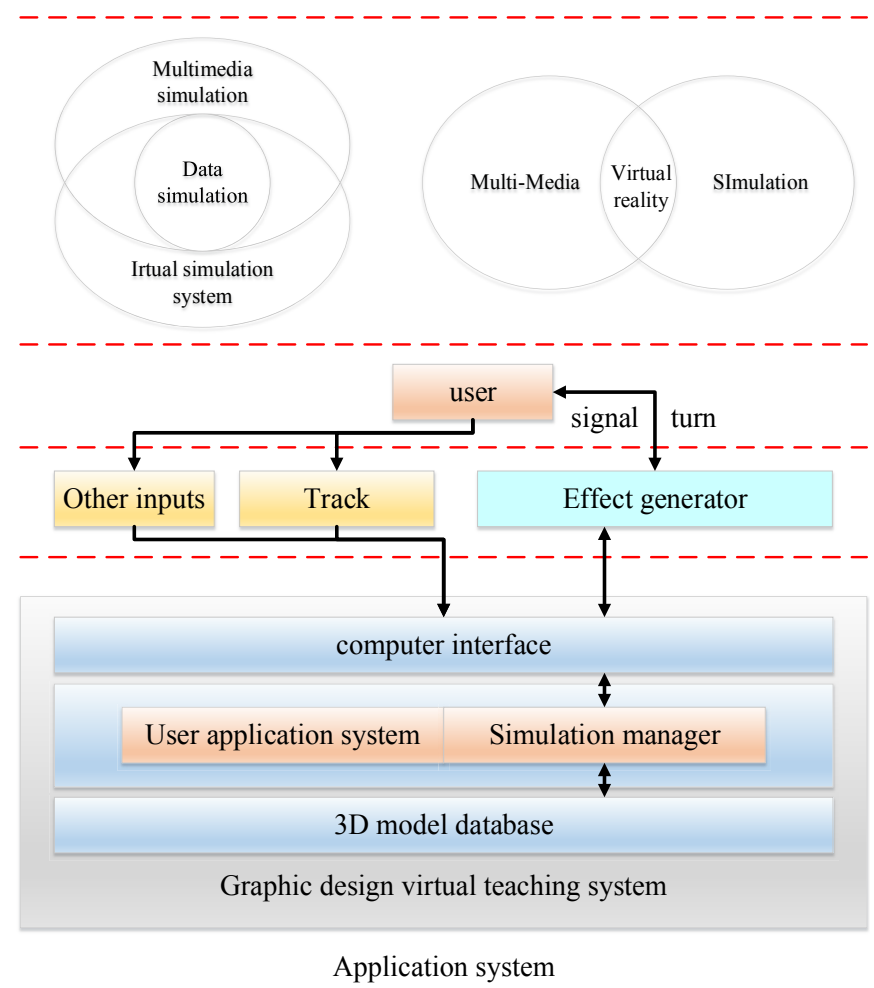

Fig. 2. Composition of virtual reality system 


\subsection{Combination of painting-imitating teaching with virtual reality technology}

Painting-imitating teaching method refers to the process of comprehending the design thought and idea of the author while imitating excellent three-dimensional effect pictures, and mastering the use of relevant virtual reality tools and software [13]. In the teaching process, various tools and methods can be adopted to guide students to make attempts, have imagination, figure out a modeling method suitable for themselves via experiment, learn to imitate and draw effect picture with software, and sum up experience by comparing differences and thinking about the reasons for the differences.

Color is an important factor of graphic design. The application of color makes a big difference in the presentation of works. For common 3D programming, RGB space is adopted to obtain other colors by changing and overlapping the colors of the three channels $(\mathrm{R}, \mathrm{G}, \mathrm{B})$. The computational formula of RGB color blending is:

$$
\text { Colour }=(65536 * \text { RED })+(256 * \text { Green })+\text { Blue }
$$

In actual graphic design practice, art designer usually adopt HSV, which is easier for adjusting the saturability and brightness. The conversion formula between HSV and RGB is as below.

$$
\begin{aligned}
& h i=\left[\frac{h}{60}\right] \bmod 6 \\
& f=\frac{h}{60}-h i \\
& p=v^{*}(1-s) \\
& q=v^{*}\left(1-f^{*} s\right) \\
& t=v^{*}(1-(1-f) * s) \\
& (r, g, b)=\left\{\begin{array}{l}
(v, t, p), h i=0 \\
(q, v, p), h i=1 \\
(p, v, t), h i=2 \\
(p, q, v), h i=3 \\
(t, p, v), h i=4 \\
(v, p, q), h i=5
\end{array}\right.
\end{aligned}
$$

The mixture of the three primary colors of red, green and blue in different proportions can produce different colors. In the night when the light is weak, it is hard for designer to perceive colors accurately, and guarantee the overall effect of works. Thus, a special color palette for graphic design can be employed. This type of color palette is provided with a fluorescent ring which can light in the night to help ensure the precision of processing works. Fig. 3 shows screenshot of the application effect of combining painting-imitating teaching with virtual reality technology. 


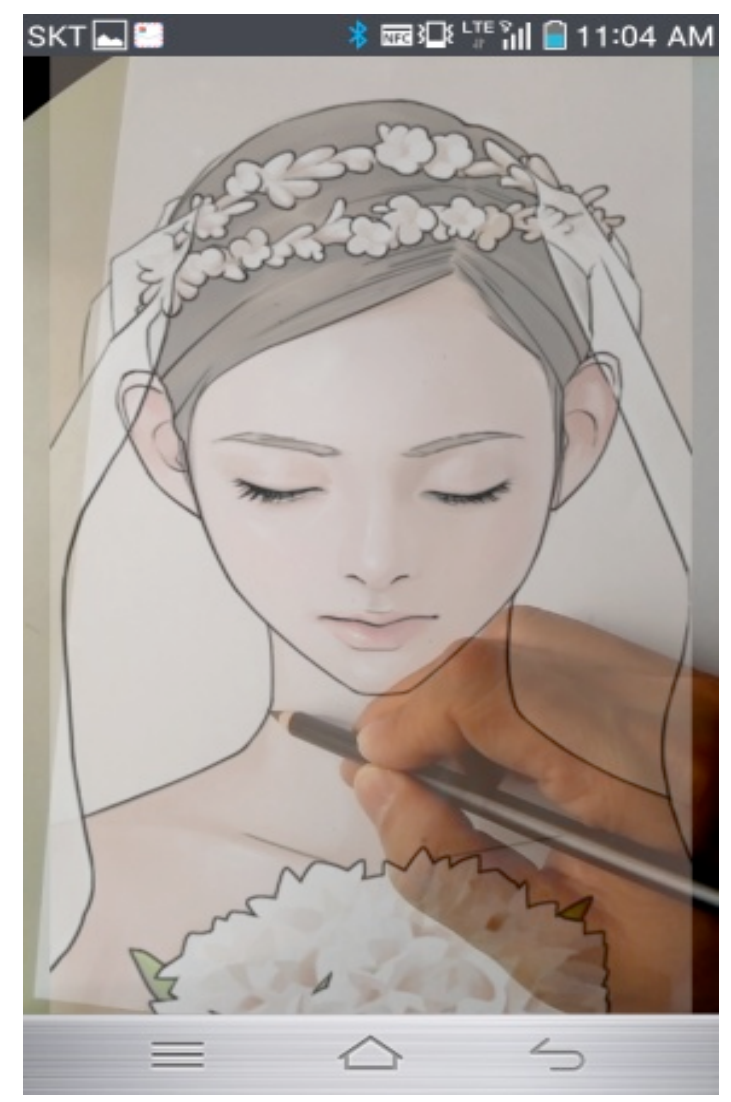

Fig. 3. Screenshot of application effect of combining painting-imitating teaching with virtual reality technology

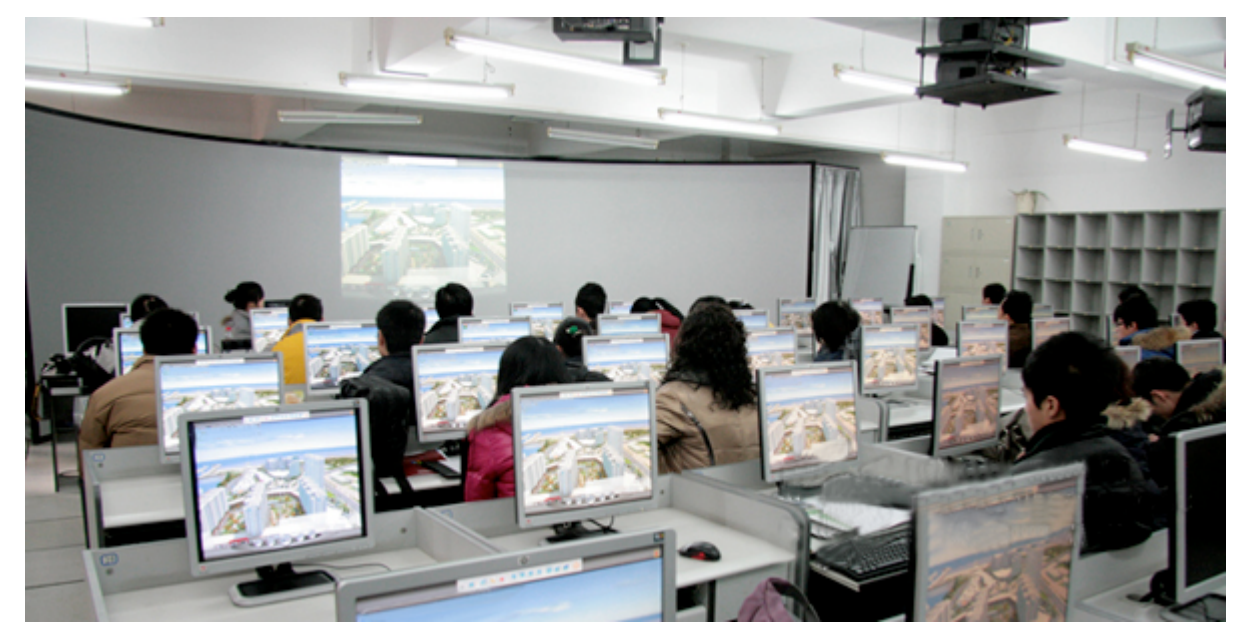

Fig. 4. Application of virtual reality technology in classroom teaching 


\section{Development of virtual reality teaching system for the course of graphic design}

VRML is a virtual reality modeling language. Based on modeling language, a lot of tools for scene creation have been produced. The following is about the creation of VRML scene with 3DStudio Max.

For purpose of this paper, case study of the design of a wall was made. To make the wall attractive, it was designed to be with some patterns harmonious with the hue and style of the whole room to beautify the wall. For the design, three-dimensional modeling modification method was adopted. A basic model was built first, which was constantly optimized by modifying the parameters according to commands and finally exported. It can be recognized and run with VRML language.

\subsection{Basic modeling}

The steps are: put all files and images related to the user interface under the same directory path (which can be directly cited as file for scene construction), construct a node $\mathrm{d}$ in the scene, and add proper button (the value of the button object covers run time, position, height, state and such information) to the menu and dialog box for controlling the node images.

Cite the image exposedField String pic, modify the state of the node by means of parameter assignment. Take the example of button click event. The SFBool state has two values. TRUE means the button is pitched on, and FASLE means the button fails to be pitched on. Add the defined pictures onto the blank wall.

DEF floor Transform \{

The implementation result is as shown in Fig. 5. In the three-dimensional model diagram of an empty room, the original drawing of the wall is blank. To beautify the wall, the wall is designed to be with decorative patterns to obtain the basic design drawing as shown in Fig. 6.

\subsection{Texture color}

For the making of the system scene model, UVW chartlet was adopted. Since the objects are in different shapes, the charlet modes also varies. Common charlet modes include plane, surface, cube, cylinder, sphere, etc. UVW chartlet has its own independent coordinates. To be consistent with the surface distribution of the model, the mode and dimension of manifesting UVW chartlet on the surface of objects, to show the texture details of model surface clearly. Besides, it should be maintained that objects are always linked together after texture processing of image objects, so as to prevent model picture from breaking or slipting up to achieve natural and satisfactory effect.

According to the definition above, if the parameter value is 0 , it means that no change happens in this direction. Texture transformation can be realized by replacing the original texture chartlet coordinates with the new charlet coordinates. 
As shown in Fig. 7, the texture and color have been changed, so as to harmonize with the wood texture and the color of brown.

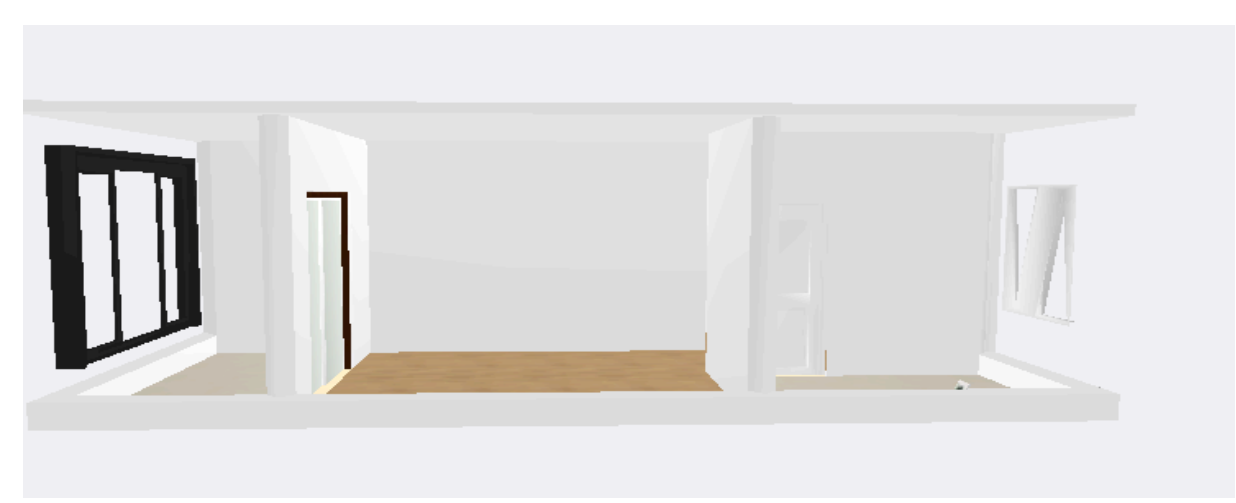

Fig. 5. Original drawing of wall designed with virtual reality technology

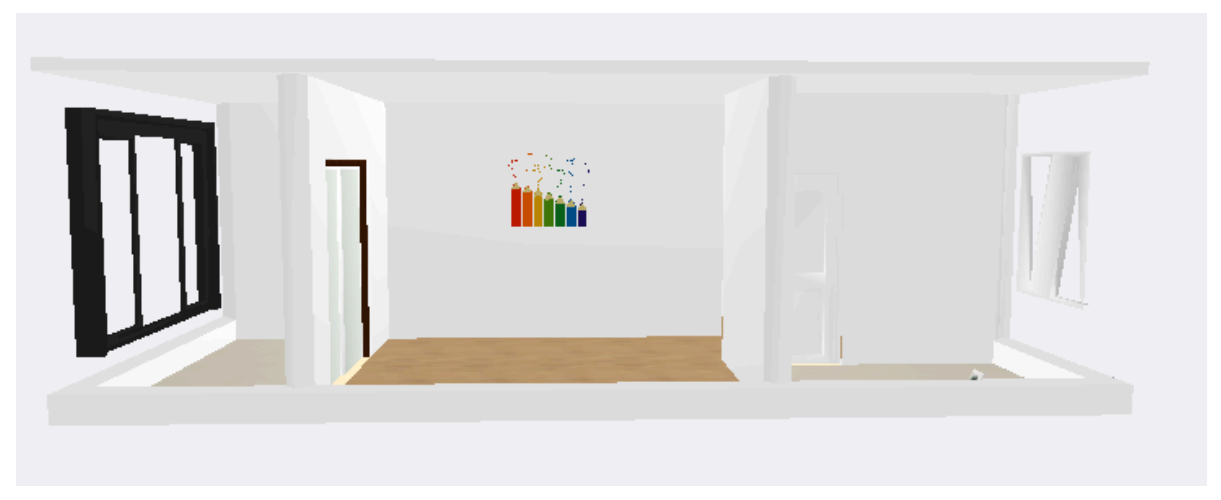

Fig. 6. Process of wall design with virtual reality technology

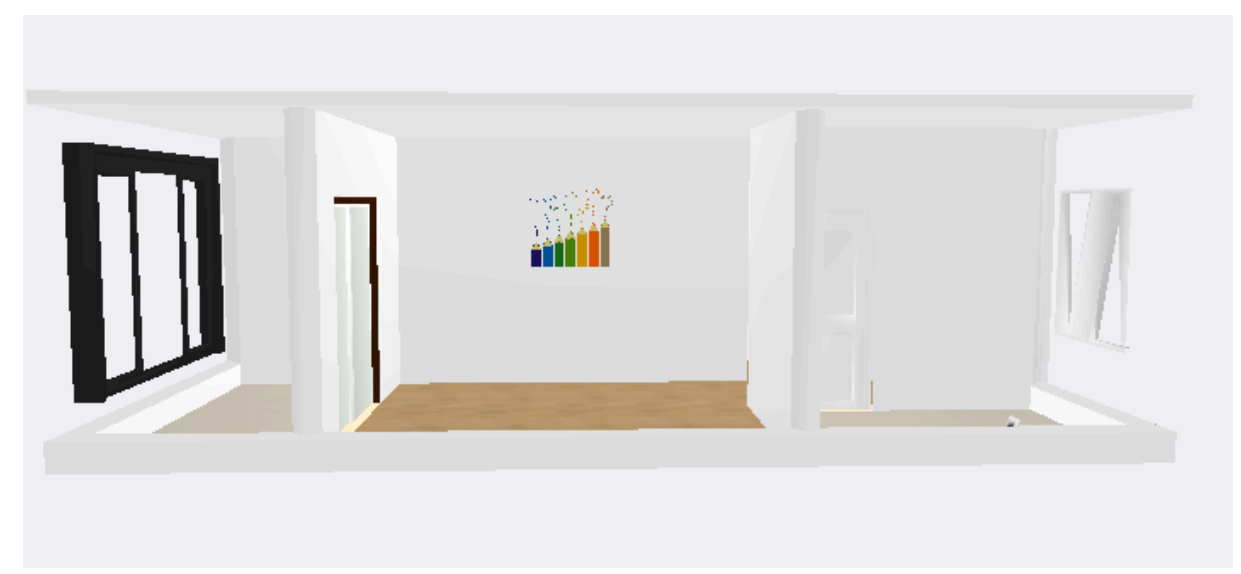

Fig. 7. Texture and color change of wall design with virtual reality technology 


\subsection{Model optimization}

Set the graph parameters rationally according to the actual situation, such as "bend", "inverse", and "length and width adjustment", etc. Fig. 8 shows one of the typical practices of parameter adjustment, via which length, width, height, ground clearance and angle can be modified. Based on different parameters, the design graph will appear in different modes. Fig. 7 shows a pattern after being adjusted. It can be seen that the angle, scale and integral form all are different from that of the original design drawing, which has become more harmonious with the whole wall and room.

For modeling, designers usually cannot achieve high accuracy and high speed at the same time. Thus, they need to balance the accuracy and speed. BSP algorithm is an optimization algorithm applicable for $3 \mathrm{D}$ model, which is useful for speeding up modeling and drawing.

\subsection{Viewpoint change}

In this system, the spatial position and orientation of the three-dimensional model can be changed, and the viewpoint of observing virtual content can be switched to browse the scene of virtual space. The Viewpoint node is needed to change the viewpoint. The three parameters of Position, orientation and fieldOfView defined by the Viewpoint node stand for three-dimensional coordinates, rotation angle and spread angle respectively, which all will have an effect on the presentation of the threedimensional model. Fig. 7 shows overall effect diagram after changing the angle with virtual reality technology. Designers can judge the rationality and aesthetic measure of the design graph more accurately by observing the design effect from different angles, so that designers can make modification and adjustment properly. Fig. 9 shows adjustment diagram of wall design angle with virtual reality technology.

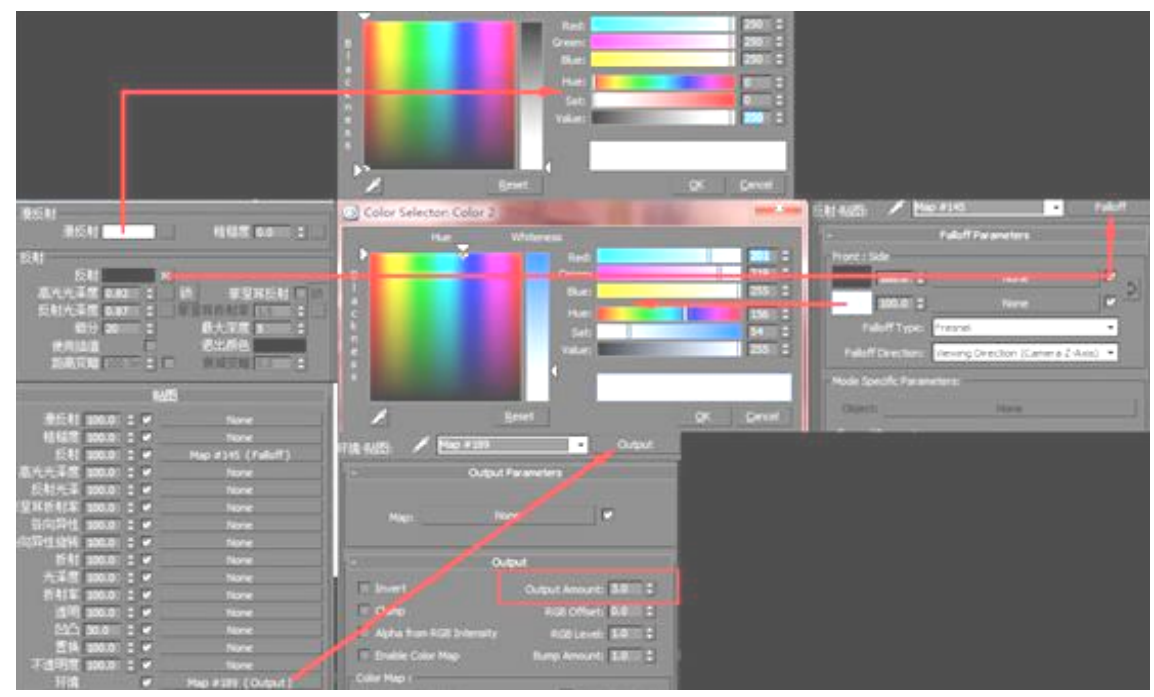

Fig. 8. Application of virtual reality technology in parameter adjustment 


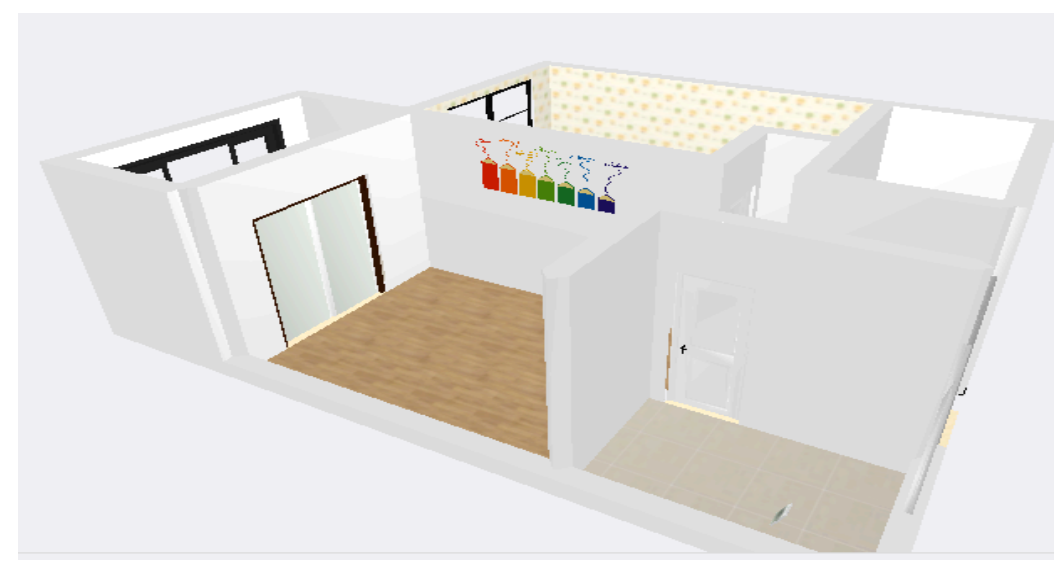

Fig. 9. Adjustment diagram of wall design angle with virtual reality technology

\subsection{Model export}

The scene and model made with professional graphic design software can be recognized with VRML language after being transformed into .wrl file. Select the export option of the menu, select the file format of .wrl, set the attributes of VRML file in the pop-up dialog box, and save it. The file exported in this way can be recognized and edited in VRML environment, and be browsed and run in VRML scene smoothly. Fig. 10 shows student's design process with professional graphic design software.

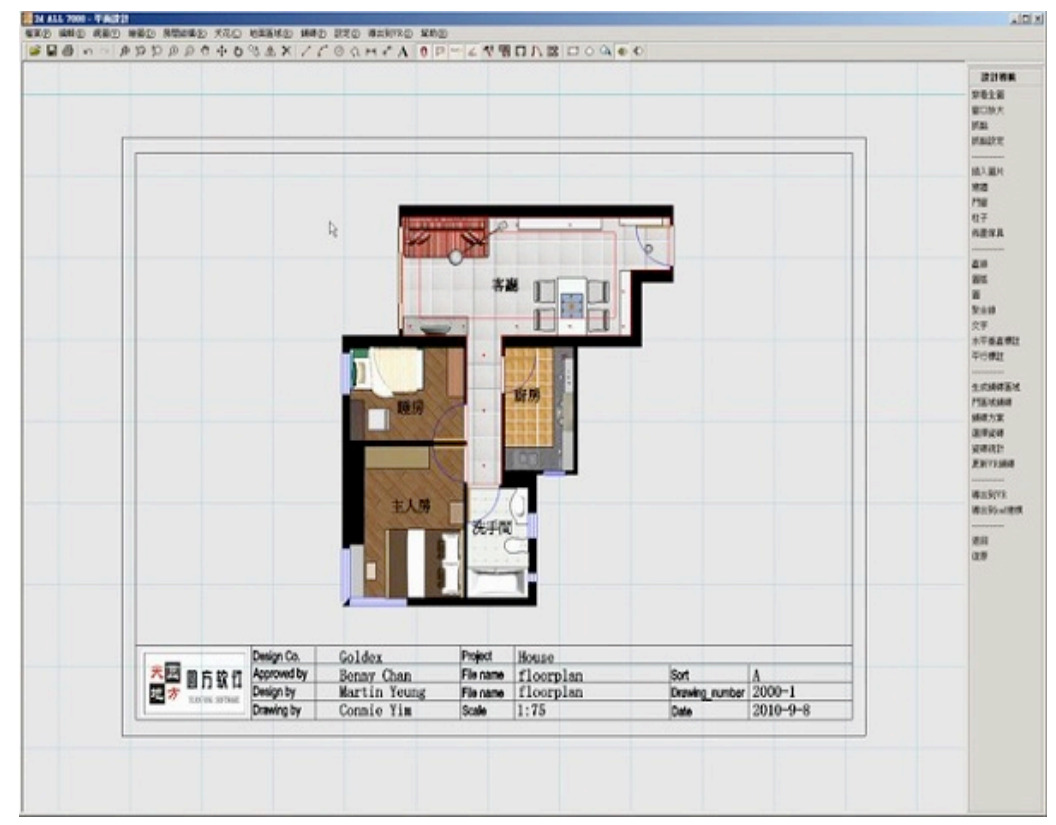

Fig. 10.Students' design process with professional graphic design software 


\subsection{Effect check}

To check the effect of the teaching method designed in this paper, a case study of the course of Graphic Design was carried out. Two 30-student classes (Class A and Class B) of undergraduate students were surveyed. For Class A, painting-imitating teaching method aided with virtual reality technology was adopted, so that students could consolidate and review the learned knowledge with virtual reality software tools after class; for Class B, the traditional teaching method was adopted, mainly including slide presentation and interpretation, visual case appreciation, and paper experiment after class. After 64 class hours (16 weeks), a questionnaire survey was carried out on the students of the two classes to analyze and study the teaching effect. The survey result is as in table 1 and table 2 .

According to Tab. 1, under the same conditions, the class for which virtual reality teaching tools were adopted is significantly superior to the class for which the traditional teaching method was adopted in respect of the degree of proficiency of course teaching skills, special imagination, students' concentration, and consolidation of knowledge after class, especially in respect of students' concentration and special imagination.

According to Tab. 2, the class for which painting-imitating teaching method was adopted is superior to the class for which the traditional teaching method was adopted in respect of proficiency in knowledge points, sensibility of art and software operating ability. This indicates that painting-imitating teaching is helpful for students to identify problems and their defects, and improve their operating ability and learning efficiency.

Table 1. Survey on effect of virtual reality teaching technology on course learning

\begin{tabular}{|l|c|c|c|c|}
\hline \multicolumn{1}{|c|}{ Class } & $\begin{array}{c}\text { Help master } \\
\text { teaching course } \\
\text { skills }\end{array}$ & $\begin{array}{c}\text { Help think and } \\
\text { develop special } \\
\text { imagination }\end{array}$ & $\begin{array}{c}\text { Help strengthen } \\
\text { students' concen- } \\
\text { tration }\end{array}$ & $\begin{array}{c}\text { Help students } \\
\text { consolidate } \\
\text { knowledge after } \\
\text { class }\end{array}$ \\
\hline Experimental Class (A) & $77.7 \%$ & $83.3 \%$ & $73.3 \%$ & $73.3 \%$ \\
\hline Control Class (B) & $40 \%$ & $34 \%$ & $37.5 \%$ & $45 \%$ \\
\hline
\end{tabular}

Table 2. Comments of the two groups on teaching methods $(\mathrm{N}=100)$

\begin{tabular}{|l|c|c|c|}
\hline \multicolumn{1}{|c|}{ Class } & $\begin{array}{c}\text { Proficiency in knowledge } \\
\text { points }\end{array}$ & Sensibility of art & $\begin{array}{c}\text { Software operating } \\
\text { ability }\end{array}$ \\
\hline Experimental Class (A) & $70.5 \%$ & $72 \%$ & $85 \%$ \\
\hline Control Class (B) & $55 \%$ & $58.5 \%$ & $62 \%$ \\
\hline
\end{tabular}

\section{Conclusions}

The combination of painting-imitating teaching method with virtual reality technology was applied in actual teaching process, and compared with traditional teaching mode. An analysis was made on the experimental results by means of questionnaire, 
indicating that the combination has improved students' active participation initiative and aroused students' learning interest.

To sum up, the effect of the combination of painting-imitating teaching method with virtual reality technology designed in this research can be checked via social practice only. Thus, we suggest to appoint designers to deliver lessons, who can explain the skills of design and drawing of effect pictures with virtual reality technology, and show students in design factory and construction site to feel effect pictures and site construction in short distance, and comprehend the connotations of design ideas and technologies, to lay a solid foundation for the study and work in future.

\section{Acknowledgment}

This work was supported in part by the 2016 Education Reform Program of Liaoning Province.

\section{$7 \quad$ References}

[1] Ma, L.L. Analysis of practice teaching of graphic art design. Journal of Jiamusi Education Institute, 2014, no. 1, pp. 236-236.

[2] Qiu, L.L. Research on Integration of Modern Logo Design Teaching and Traditional Graphic Art. Journal of Changzhou Vocational College of Information Technology, 2014, vol. 13(3), pp. 62-64.

[3] Vora, J., Nair, S., Gramopadhye, A.K., et al. Using virtual reality technology for aircraft visual inspection training: presence and comparison studies. Applied Ergonomics, 2002, vol. 33(6), pp. 559-570. https://doi.org/10.1016/S0003-6870(02)00039-X

[4] Shin, Y. Virtual reality simulations in Web - based science education. Computer Applications in Engineering Education, 2010, vol. 10(1), pp. 18-25. https://doi.org/10.1002/cae.10 $\underline{014}$

[5] Schultheis, M.T., Rizzo, A.A. The application of virtual reality technology in rehabilitation. Rehabilitation Psychology, 2001, vol. 46(3), pp. 296-311. https://doi.org/10.1037/ 0090-5550.46.3.296

[6] Yang, J.C., Chen, C.H., Ming, C.J. Integrating video-capture virtual reality technology into a physically interactive learning environment for English learning. Computers \& Education, 2010, vol. 55(3), pp. 1346-1356. https://doi.org/10.1016/j.compedu.2010.06.005

[7] Pereira, A.E. Virtual Reality and Real Emotionality - the Nature of Video Chat Encounters. International Journal of Internet of Things, 2012, vol. 1(1), pp. 1-8.

[8] Huang, Y.X. Application of virtual teaching based on VR Technology. Electronic Technology \& Software Engineering, 2017, vol. 6(9), pp. 136-136.

[9] Wang, F., Wang, Y., Zeng, R., et al. Research on Construction of Preview Type of Physical Virtual Experiment Platform. China Modern Educational Equipment, 2016, vol. 14(3), pp. 9-11.

[10] Chen, H.B., Wang, T. Design and Accomplishment of a Real Time Walkthrough System in Virtual Archite cture Environment. Journal of Southwest Jiaotong University, 2001, vol. 36(1), pp. 53-56. 
[11] Nian, L., Lian, J.M., Pan, C.P., et al. Modeling and Simulating of Force Models in Control Loading System of Flight Simulator. Control and Automation, 2010, vol. 26(34), pp. 196197.

[12] Chen, C.H., Yang, J.C., Shen, S., et al. A Desktop Virtual Reality Earth Motion System in Astronomy Education. Journal of Educational Technology \& Society, 2007, vol. 10(3), pp. 289-304.

[13] Shim, K.C., Park, J.S., Kim, H.S., et al. Application of virtual reality technology in biology education. Journal of Biological Education, 2003, 37(2):71-74. https://doi.org/10.1080/002 $\underline{19266.2003 .9655854}$

\section{Author}

Mingying Lou is an associate professor in the University of Science and Technology Liaoning, Anshan 114051, China. (mingying10567@163.com)

Article submitted 24 March 2017. Published as resubmitted by the author 20 June 2017. 